\title{
From the Editors' Desk: Patient Autonomy and Medical Decisions: Getting it Just Right
}

\author{
Mitchell D. Feldman, MD, MPhil \\ University of California, San Francisco, San Francisco, CA, USA.
}

J Gen Intern Med 25(7):639

DOI: $10.1007 / \mathrm{s} 11606-010-1391-0$

(c) The Author(s) 2010. This article is published with open access at Springerlink.com

$\mathrm{O}$ nce upon time, patients relied on physicians to tell them what to do when faced with a medical decision, and for the most part, physicians gladly accepted this responsibility. Eventually, patients and doctors came to realize that this paternalistic approach to medical decision-making placed far too much power in the hands of physicians, however beneficent their intent.

Over the past 20 years or so, in part fueled by the growing interest in decision-making at the end of life, there has been a seismic change in the approach to medical decision-making and the physician-patient relationship, with increasing emphasis on a model that emphasizes patient autonomy and shared decision-making. In the extreme expression of this model, the role of the health care provider is simply to provide accurate information to patients without sharing their own views or experiences; patients are expected to make the tough medical decisions on their own, whether it be treatment preferences at the end of life or choice of medication in chronic disease management. In contrast with medical paternalism, this model places far too little responsibility on physicians to exercise their expertise with patients when faced with a difficult choice.

In this issue of JGIM, Entwistle et al. argue that it is time for us to broaden the discussion of patient autonomy beyond a narrow focus on medical decision-making to one that shifts the focus to the relational context of the physician-patient

Published online May 15, 2010 relationship. They assert that a relational approach to patient autonomy allows the clinician to better understand the individual patient in a broader social/cultural context and therefore to support patient autonomy in a diversity of health care contexts. Original research articles by Beach et al. and Nguyen et al. also in this issue remind us that language, culture and socio-economic status often have a profound influence on patient-doctor communication and health related behavior. For example, Beach found that there was less patient centered communication in encounters between HIV-infected Hispanic patients and their providers compared with white patients, though surprisingly, Hispanics reported higher overall satisfaction.

A Pubmed search using the search term "patient autonomy" reveals more than 12,000 published scholarly articles, 42 in JGIM alone in the past 20 years. We have come a long way since the days of physician paternalism but have not yet reached a satisfactory balance between the dual goals of respect for patient autonomy and the need for physicians to respectfully and clearly share their expertise and ideas. Clearly, when it comes to patient autonomy and medical decision-making, we are still trying to figure out how to get it just right.

Open Access: This article is distributed under the terms of the Creative Commons Attribution Noncommercial License which permits any noncommercial use, distribution, and reproduction in any medium, provided the original author(s) and source are credited.

Corresponding Author: Mitchell D. Feldman, MD, MPhil; University of California, San Francisco, San Francisco, CA, USA (e-mail: mfeld man@medicine.ucsf.edu). 